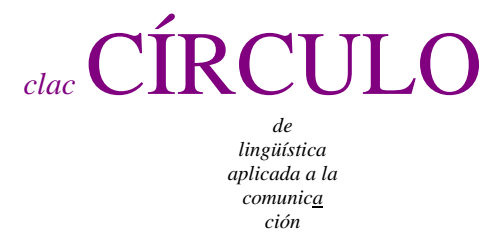

$61 / 2015$

\title{
EL SISTEMA PRONOMINAL ÁTONO DE TERCERA PERSONA EN EL ESPAÑOL HABLADO POR LOS MALECUS DE COSTA RICA
}

\author{
Carlos Sánchez Avendaño \\ Universidad de Costa Rica \\ carlos.sanchezavendan en ucr.ac.cr
}

\section{Resumen}

En este trabajo se describe el sistema pronominal átono de objeto directo de tercera persona en el español hablado por los malecus de Costa Rica de acuerdo con las variables ‘generación’ y ‘comunidad de procedencia', los dos factores que han mostrado correlación con el tipo de bilingüismo en este grupo. En la generación con bilingüismo subordinado al malecu (ancianos y adultos mayores), se encuentra variación libre entre los clíticos lo la los las (e incluso se documentan casos de leísmo, loísmo y laísmo), así como reduplicación con un grupo nominal correferencial a la derecha del verbo, si bien parece predominar el clítico lo. Esta variación se estabiliza en las generaciones sucesivas con una tendencia a la neutralización de las categorías de género y número a favor del archimorfema lo. Dicho cambio, sin embargo, disminuye en correlación con el factor generacional.

Palabras clave: español de contacto, sistema pronominal átono, cambios inducidos por contacto, malecu

Sánchez Avedaño, Carlos. 2015.

El sistema pronominal átono de $3^{\mathrm{a}}$ persona en el español hablado por los malecus de Costa Rica.

Círculo de Lingüística Aplicada a la Comunicación 61, 79-103.

http://www.ucm.es/info/circulo/no61/sanchez.pdf

http://revistas.ucm.es/index.php/CLAC

http://dx.doi.org/10.5209/rev_CLAC.2015.v61.48468

(C)2015 Carlos Sánchez Avedaño

Círculo de Lingüística Aplicada a la Comunicación (clac)

Universidad Complutense de Madrid. ISSN 1576-4737. http://www.ucm.es/info/circulo 


\begin{abstract}
In this paper, we describe the unstressed pronominal system of the direct object for the third person, as used by the Malecu of Costa Rica in their Spanish variety, taking into consideration their generational group and their hometown. These two variables have shown correlation to the type of bilingualism in these speakers of Spanish. In the generation with subordinate bilingualism to the Malecu (elders), we found free variation among the clitics lo la los las (and even cases of leísmo, laísmo and loísmo have been reported), as well as reduplication with a correferential nominal group placed to the right of the verb, though the clitic lo seems to predominate. This variation stabilizes in the successive generations with a tendency to the neutralization of the categories of gender and number in favor of the archimorpheme lo. Such change, however, decreases in correlation to the generational factor.
\end{abstract}

Key words: contact Spanish, unstressed pronominal system, contact-induced change, Malecu

Índice

1. Introducción, 81

2. Los sistemas pronominales átonos en las variedades de español de contacto, 83

3. El sistema pronominal átono de tercera persona en el español de los malecus, 85

3.1. Hablantes ancianos y adultos mayores, 87

3.2. Hablantes adultos y adultos jóvenes, 91

3.3. Hablantes jóvenes, 93

3.4. Hablantes niños, 94

3.5. El corpus de elicitación controlada y los datos de habla espontánea, 95

4. Cambios inducidos por contacto en el sistema pronominal átono de tercera persona en el español malecu, 96

5. Conclusiones, 100

Bibiografía, 101 


\section{Introducción}

Los malecus (o guatusos) constituyen uno de los nueve grupos amerindios asentados en el territorio de Costa Rica en la actualidad (Sánchez 2013). La mayoría de la población (unos 500 individuos) reside en el cantón de Guatuso, provincia de Alajuela, en tres comunidades: El Sol, Tonjibe y Margarita ${ }^{1}$.

Antes del siglo XVIII, la región norte de Costa Rica, donde se ubica su territorio histórico, fue considerada de indígenas insumisos (Solórzano 2013). Este hecho, aunado a su lejanía con respecto a los grandes asentamientos primero de los españoles y luego de los hispanocostarricenses, explica que su cultura tradicional, incluyendo su lengua autóctona, se conservara con muy pocos influjos hispánicos durante toda la Colonia y buena parte de la vida independiente del país.

Así, con toda seguridad su contacto con el grupo de lengua y cultura hispánicas fue sumamente esporádico y limitado al menos hasta la segunda mitad del siglo XIX, como se comprueba en la falta de referencias sobre su existencia en los documentos de las distintas épocas y en los datos que se desprenden de la misma tradición oral de este pueblo (Constenla 1988, Castillo 2004).

El contacto intenso y continuo no comenzó sino hasta mediados del siglo XX, con la fundación de una escuela en Margarita y los cambios radicales que se produjeron en el territorio a partir de este momento: usurpación paulatina del territorio histórico por parte del creciente número de campesinos nicaragüenses y costarricenses que llegaron a poblar la región, deforestación de los bosques para la creación de fincas ganaderas y agrícolas, y construcción de infraestructura vial.

De acuerdo con el informe de Porras (1959), en la década de 1950, todavía los malecus practicaban en su totalidad la religión tradicional, habitaban en las casas al estilo autóctono, mantenían sus hábitos alimenticios y hablaban con fluidez la lengua vernácula. La instalación de un sistema económico y administrativo ajeno a la cultura

\footnotetext{
${ }^{1}$ Esta investigación se desarrolló en el marco del proyecto "El español en contacto con otras lenguas: variación y cambio lingüístico”, financiado parcialmente por el Ministerio de Economía y Competitividad de España (Ref. FFI2012-31702), y como proyecto inscrito en la Vicerrectoría de Investigación de la Universidad de Costa Rica ( $\mathrm{N}^{\circ}$ 745-B3-104). Le agradezco al M.L. Henry Angulo la revisión de la traducción del resumen al inglés.
} 
tradicional de este pueblo, así como el desequilibrio demográfico y de poder llevaron a que el contacto con la lengua y la cultura hispánicas se intensificara a partir de las décadas de 1970 y 1980.

En la actualidad, de acuerdo con el diagnóstico más reciente (Sánchez 2011), su lengua autóctona se encuentra en proceso de desplazamiento, el cual se manifiesta en el cese de la transmisión intergeneracional del idioma, la reducción de sus dominios de uso y un heterogéneo continuum de competencia bilingüe (bilingüismo sucesivo con el malecu como primera lengua, bilingüismo equilibrado malecu-español, bilingüismo con el español como lengua dominante, semilingüismo, bilingüismo predominantemente receptivo en malecu y monolingüismo en español).

Son tres los factores interrelacionados que inciden en el continuum de competencia bilingüe: la comunidad de procedencia, la generación y la biografía lingüística individual. Así, se ha determinado con certeza que el proceso de desplazamiento comenzó antes en Margarita y El Sol que en Tonjibe, más o menos con unas dos décadas de diferencia, lo que implica que en este último poblado sea más común encontrar jóvenes mayores de 20 años que pueden expresarse en malecu y jóvenes menores (incluso niños) con competencia receptiva desarrollada, aunque con pocas habilidades de producción. Por el contrario, en las otras dos comunidades esto es poco frecuente (Sánchez 2011).

La biografía lingüística individual incluye casos de amplio desarrollo de habilidades productivas (un par de niños de unos 9 años, uno en Margarita y otra en Tonjibe son particularmente interesantes), de atrofia de la competencia productiva y de adquisición incompleta e incluso de intentos de adquirir el idioma después del período de niñez, vinculados con motivaciones ideológico-actitudinales (tanto de la familia como de los sujetos particulares), el núcleo familiar de socialización y la crianza o la migración fuera y dentro del territorio en distintos momentos de la vida.

Como parte de nuestras investigaciones enmarcadas en la línea de la lingüística de contacto y el desplazamiento de lenguas, en el presente trabajo nos ocupamos pormenorizadamente de sistematizar los datos con respecto al sistema pronominal átono de objeto directo de tercera persona en el español hablado por los malecus, tema que no ha sido siquiera mencionado en las exiguas descripciones sobre fenómenos particulares 
del español de este pueblo (Constenla 2005, Quesada 2008). De este modo, intentamos dar cuenta de un cambio gramatical presente en el español malecu desde la perspectiva de la lingüística de contacto y en relación con la situación sociolingüística reseñada párrafos atrás.

2. Los sistemas pronominales átonos en las variedades de español de contacto

Frente a la tendencia de buscar préstamos y transferencias directas de elementos lingüísticos de una lengua a otra en situaciones de contacto, Palacios (2008) indica que no hay que olvidar que la influencia de la lengua vernácula puede consistir en incentivar un cambio estructural incipiente ya presente en la segunda lengua más que una importación de una estructura como tal (los denominados "cambios indirectos por convergencia” o “cambios inducidos por contacto"), en un proceso complejo relacionado con las estrategias comunicativas de que dispone el hablante:

Entiendo los cambios indirectos inducidos por contacto como cambios multicausales compatibles con las tendencias internas del sistema. Este tipo de cambio ha sido motivado tanto interna (evolución interna de la lengua) como externamente (por el contacto con otras lenguas). No supone importación de material ajeno, ya que el cambio lingüístico se produce a partir de una variación ya existente en la lengua. Así, mediante la influencia indirecta de una lengua en contacto A surgen variaciones gramaticales muy significativas, generalmente en el registro oral coloquial de la lengua $\mathrm{B}$, que aprovechan la propia evolución interna de esa lengua B para hacer aflorar estrategias gramaticales cuya funcionalidad comunicativa obedece a procesos cognitivos de la lengua A de contacto. (Palacios 2011, 25-26)

También hay que notar, según esta autora, que se encuentran constantes en los cambios gramaticales del español, aunque las lenguas en contacto sean diferentes, por lo general en los sistemas pronominal, de marcación de casos, preposicional y verbal, así como en la concordancia, los artículos, la marcación del género y el orden de palabras. Esto se debería, según Palacios (2011), a que se trata de “áreas” de la morfosintaxis del español inestables y más propensas al cambio, sea que este se encuentre ya en marcha y se 
acelere por efecto del contacto, que se desdibujen las restricciones de tipo lingüístico que limitan su extensión, que se produzca una restructuración del subsistema gramatical completo o que los repertorios idiomáticos disponibles adquieran nuevos valores semánticos.

Tales cambios son acelerados precisamente por la reinterpretación y reorganización de los sistemas gramaticales del español por influjo de la organización lingüísticocognitiva de la lengua amerindia de contacto. Por ejemplo, Palacios aduce que los cambios documentados en los sistemas pronominales átonos de tercera persona en distintas variedades del español hablado en regiones de bilingüismo histórico aprovechan la inestabilidad de tal sistema, que en la variedad peninsular sin influjo de otro idioma muestra una tendencia a privilegiar la marcación del género (de ahí el leísmo y el laísmo) por encima de la del caso, como lo han descrito diversos lingüistas y en consonancia con universales de cambio lingüístico que predicen la neutralización del caso antes que la del número y el género.

Frente a este proceso, nos encontramos con los cambios en dicho sistema en variedades del español hispanoamericano en zonas de contacto de lenguas, a partir del sistema etimológico predominante en América, en el que se distingue morfológicamente el caso (acusativo y dativo), el género (en el caso acusativo) y el número. Como resultado, se encuentran variedades con neutralización del género en el acusativo, por ejemplo. Palacios defiende que estas variaciones tienen lugar en contra de los universales de cambio, por lo que deben ser explicadas por factores externos al sistema, particularmente como cambios inducidos por contacto con otros idiomas:

El cambio que está teniendo lugar en estos sistemas pronominales de variedades de contacto de lenguas elimina la asimetría que se da en el sistema etimológico entre el objeto directo y el indirecto. Así, se equiparan las manifestaciones de las formas pronominales de ambos objetos: le será el marcador de objeto indirecto y lo del directo, indistintamente del género de sus antecedentes. En otras palabras, la marcación del género del referente no condicionará la selección de las formas pronominales de objeto indirecto o directo, a diferencia de lo que ocurre en el español estándar americano de las áreas sin contacto con lenguas amerindias que rodea estas zonas bilingües. (Palacios 2011, 29) 
Evidentemente, como lo hace Palacios, debe encontrarse la motivación estructuralcognitiva en la lengua de contacto que haya promovido el cambio en una dirección distinta a la esperable por acción de las tendencias universales. Por lo tanto, a continuación describiremos nuestros datos del sistema pronominal átono de objeto directo de tercera persona en el español hablado por los malecus $\mathrm{y}$, posteriormente, evaluaremos la tesis de Palacios con base en las características gramaticales de la codificación del caso, el género y el número en la lengua malecu.

3. El sistema pronominal átono de tercera persona en el español de los malecus

El corpus analizado proviene de ocho entrevistas individuales y doce grupos de discusión (con entre 3 y 8 participantes cada uno), que suman unas veinte horas y media (1233 minutos) de grabación sobre el desplazamiento de la cultura tradicional y la lengua vernácula (discurso deliberativo).

Hemos dividido a los participantes en doce grupos tomando en consideración tres variables: comunidad de origen, generación y competencia reportada en malecu. En el siguiente cuadro se resumen las características demosociales y lingüísticas de los hablantes con los que se obtuvo el corpus. Conviene recalcar que la variable sexo no se tomó en cuenta, pues no demostró ser relevante en nuestro estudio de la competencia lingüística (Sánchez 2011).

Cuadro 1. Distribución de hablantes por comunidad y generación

\begin{tabular}{|c|c|c|}
\hline Comunidad & Grupo generacional & Cantidad de participantes y tipo de bilingüismo \\
\hline \multirow[t]{4}{*}{ Margarita } & Habla de jóvenes & $\begin{array}{l}17 \text { jóvenes con edades entre los } 13 \text { y los } 30 \text { años. Incluye } \\
\text { jóvenes que declaran solo competencia receptiva (amplia o } \\
\text { reducida) o competencia productiva limitada. }\end{array}$ \\
\hline & Habla de adultos & $\begin{array}{l}10 \text { adultos con edades entre los } 32 \text { y los } 40 \text { años. Incluye } \\
\text { adultos que declaran ser bilingües relativamente equilibrados } \\
\text { o con competencia productiva disminuida. Algunos son } \\
\text { bilingües simultáneos. }\end{array}$ \\
\hline & $\begin{array}{l}\text { Habla de ancianos con } \\
\text { bilingüismo equilibrado }\end{array}$ & $\begin{array}{l}2 \text { ancianos con edades entre los } 60 \text { y los } 70 \text { años. Declaran } \\
\text { competencia bilingüe relativamente equilibrada. Son } \\
\text { bilingües sucesivos. }\end{array}$ \\
\hline & $\begin{array}{l}\text { Habla de ancianos con el } \\
\text { malecu como lengua } \\
\text { dominante }\end{array}$ & $\begin{array}{l}3 \text { ancianos con edades entre los } 65 \text { y los } 80 \text { años. Declaran } \\
\text { competencia limitada en español. Claramente son bilingües } \\
\text { sucesivos. }\end{array}$ \\
\hline
\end{tabular}




\begin{tabular}{|c|c|c|}
\hline \multirow[t]{3}{*}{ El Sol } & Habla de jóvenes & $\begin{array}{l}5 \text { jóvenes con edades entre los } 17 \text { y los } 30 \text { años. Declaran } \\
\text { competencia productiva limitada, pero receptiva } \\
\text { desarrollada. }\end{array}$ \\
\hline & Habla de adultos & $\begin{array}{l}4 \text { adultos con edades entre los } 33 \text { y los } 36 \text { años. Declaran } \\
\text { desde competencia activa desarrollada hasta limitada (por } \\
\text { adquisición incompleta). }\end{array}$ \\
\hline & $\begin{array}{l}\text { Habla de adultos } \\
\text { mayores }\end{array}$ & $\begin{array}{l}2 \text { adultos mayores con edades entre los } 54 \text { y los } 57 \text { años. } \\
\text { Declaran competencia equilibrada en ambas lenguas, pero } \\
\text { claramente son bilingües sucesivos. }\end{array}$ \\
\hline \multirow[t]{5}{*}{ Tonjibe } & Habla de niños & $\begin{array}{l}6 \text { niños con edades entre los } 9 \text { y los } 13 \text { años. Se trata de } \\
\text { niños con cierta competencia receptiva, pero con muchas } \\
\text { limitaciones para producir en malecu. }\end{array}$ \\
\hline & Habla de jóvenes & $\begin{array}{l}11 \text { jóvenes con edades entre los } 14 \text { y los } 26 \text { años. Declaran } \\
\text { desde competencia productiva limitada hasta desarrollada. } \\
\text { Todos son bilingües receptivos. }\end{array}$ \\
\hline & $\begin{array}{l}\text { Habla de adultos con } \\
\text { bilingüismo equilibrado }\end{array}$ & $\begin{array}{l}4 \text { adultos con edades entre los } 33 \text { y los } 46 \text { años. Se trata de } \\
\text { bilingües equilibrados, pero sucesivos. }\end{array}$ \\
\hline & $\begin{array}{l}\text { Habla de adultos con el } \\
\text { español como lengua } \\
\text { dominante }\end{array}$ & $\begin{array}{l}2 \text { adultos con edades entre los } 40 \text { y los } 50 \text { años. Se trata de } \\
\text { dos adultos con bilingüismo sobre todo receptivo en malecu. }\end{array}$ \\
\hline & Habla de ancianos & $\begin{array}{l}4 \text { ancianos con edades entre } 58 \text { y los } 64 \text { años. Declaran } \\
\text { competencia productiva limitada en español. Claramente } \\
\text { son bilingües sucesivos. }\end{array}$ \\
\hline
\end{tabular}

Como señalamos en Sánchez (2011) en cuanto a los perfiles sociolingüísticos por grupos generacionales, la terminología concerniente a los tipos de bilingüismo que empleamos describe de manera aproximada el momento de adquisición (bilingüismo sucesivo y bilingüismo simultáneo) y la competencia lingüística (bilingüismo equilibrado y bilingüismo subordinado con el malecu o el español como lengua dominante), según lo reportado por los individuos. Si bien mucha de esta información se ha contrastado mediante observación in situ, no se basa en mediciones especializadas de la competencia lingüística de los hablantes.

Para el análisis, procedimos a registrar todas las apariciones de clíticos de objeto directo, excepto cuando estos formaban parte de una locución con clítico fosilizado (por ejemplo, verla fea, jugársela, tirárselas de algo, digámoslo asî). No se incluyen en el análisis tampoco los clíticos cuyo referente endofórico no fue posible determinar con certeza ni los que corresponden a referentes oracionales. 
Para la presentación de los resultados, se tomará como punto de partida la variable 'tipo de bilingüismo por momento de adquisición’ (vinculada con la generación) en relación con cada una de las tres comunidades. Para mayores detalles al respecto, remitimos al estudio pormenorizado en Sánchez (2011), de donde reseñamos la información más pertinente para el presente trabajo. La importancia de tales perfiles sociolingüísticos es puesta de relieve por Blas (2008) como requisito para poder llevar a cabo un acercamiento apropiado a los fenómenos de contacto de lenguas.

Tómese en cuenta que el corpus de discurso deliberativo nos permite cuantificar la aparición de cada uno de los clíticos en relación con los rasgos morfosintácticos de género y número del grupo nominal correferencial respectivo, pero nuestra impresión fundamentada en nuestro contacto con miembros de la comunidad por más de cuatro años- es que en algunos casos el fenómeno de variación está infrarrepresentado en comparación con los datos que se podrían registrar en el habla coloquial espontánea (es decir, en este caso, por ejemplo, la neutralización de género resulta mucho más frecuente), motivo por el cual aludiremos a este tipo de información al final de este apartado.

\subsection{Hablantes ancianos y adultos mayores}

De acuerdo con la categorización etaria ad hoc que formulamos a partir de nuestro conocimiento de las circunstancias de vida del pueblo malecu y su devenir histórico reciente (ver Sánchez 2011), el bilingüismo de los adultos mayores (de aproximadamente 50 años) y los ancianos (mayores de 65 años) se puede caracterizar como sucesivo, con el malecu como idioma dominante.

En nuestros datos se encuentran, sin embargo, dos grupos: en las personas mayores de 70 años en Margarita y en las mayores de 55 en Tonjibe, se halla una variedad de español caracterizable como interlengua con variantes de desarrollo fosilizadas (Appel y Muysken 1996), las cuales incluyen múltiples discordancias, construcciones morfosintácticas idiosincráticas y neologismos léxicos (Sánchez, en preparación), mientras que en las menores a estos rangos de edad en las respectivas comunidades no se aprecian muchos de esos fenómenos. El primer grupo no asistió a la escuela o no 
llegó a pasar de los niveles más elementales. Como hemos podido recoger datos de ambos grupos en la comunidad de Margarita, los tratamos por separado en el cuadro 2.

Cuadro 2. Aparición de clíticos de objeto directo en el habla de ancianos y adultos mayores

\begin{tabular}{|c|c|c|c|c|c|}
\hline & \multirow[t]{2}{*}{ Clítico } & \multicolumn{2}{|l|}{ Margarita } & \multirow[t]{2}{*}{ El Sol } & \multirow[t]{2}{*}{ Tonjibe } \\
\hline & & $\begin{array}{l}\text { Con malecu } \\
\text { dominante }\end{array}$ & $\begin{array}{l}\text { Con } \\
\text { bilingüismo } \\
\text { equilibrado }\end{array}$ & & \\
\hline \multirow{3}{*}{$\begin{array}{l}\text { Referente masculino } \\
\text { singular }\end{array}$} & lo & 21 / 78\% & 54 / 100\% & 49 / 91\% & 17 / $94 \%$ \\
\hline & la & 0 & 0 & $5 / 9 \%$ & $1 / 6 \%$ \\
\hline & le & $6 / 22 \%$ & 0 & 0 & 0 \\
\hline \multirow{2}{*}{$\begin{array}{l}\text { Referente masc. sng. con } \\
\text { reduplicación }\end{array}$} & lo & $6 / 86 \%$ & 0 & 0 & $3 / 100 \%$ \\
\hline & le & $1 / 14 \%$ & 0 & 0 & 0 \\
\hline \multirow{3}{*}{$\begin{array}{l}\text { Referente femenino } \\
\text { singular }\end{array}$} & lo & 5 / 100\% & $9 / 64 \%$ & 12 / 60\% & $11 / 92 \%$ \\
\hline & la & 0 & $5 / 36 \%$ & $8 / 20 \%$ & 0 \\
\hline & le & 0 & 0 & 0 & $1 / 8 \%$ \\
\hline $\begin{array}{l}\text { Referente fem. sing. con } \\
\text { reduplicación }\end{array}$ & lo & 0 & 0 & $1 / 100 \%$ & $1 / 100 \%$ \\
\hline \multirow{4}{*}{$\begin{array}{l}\text { Referente masculino } \\
\text { plural }\end{array}$} & lo & $1 / 20 \%$ & $8 / 53 \%$ & $6 / 46 \%$ & $5 / 83 \%$ \\
\hline & la & $1 / 20 \%$ & $2 / 13 \%$ & $1 / 8 \%$ & 0 \\
\hline & los & $3 / 60 \%$ & $5 / 33 \%$ & $2 / 15 \%$ & 0 \\
\hline & le & 0 & 0 & $4 / 31 \%$ & $1 / 17 \%$ \\
\hline \multirow{2}{*}{$\begin{array}{l}\text { Referente masculino } \\
\text { plural con reduplicación }\end{array}$} & lo & 0 & $1 / 100 \%$ & 0 & 0 \\
\hline & la & 0 & 0 & $1 / 100 \%$ & 0 \\
\hline \multirow{4}{*}{$\begin{array}{l}\text { Referente femenino } \\
\text { plural }\end{array}$} & lo & 4 / 100\% & $5 / 71 \%$ & $3 / 37,5 \%$ & $3 / 100 \%$ \\
\hline & las & 0 & $1 / 14 \%$ & $3 / 37,5 \%$ & 0 \\
\hline & los & 0 & $1 / 14 \%$ & $1 / 12,5 \%$ & 0 \\
\hline & le & 0 & 0 & $1 / 12,5 \%$ & 0 \\
\hline
\end{tabular}

Como se puede apreciar, predomina la neutralización del género a favor del clítico lo cuando el referente es femenino, sea no animado (ejemplos 1 y 2), animado (ejemplo 3) 
o humano (ejemplo 4), incluso con reduplicación (ejemplo 5), en consonancia con lo descrito para otras variedades de contacto:

(1). No / esa ley aquí / con el perdón de ustedes / yo me lo paso por el trasero.

(2). Yo dejé en un ratito mi comida y me lo robaron.

(3). Pobrecita iguanita tal vez anda abajo ahí y lo agarran para comer.

(4). Nunca lo dejaron / siempre llevaron a la muchacha.

(5). Yo lo catalogo a ella / de acuerdo con mi conocimiento que ella sí es racista.

No obstante, los datos muestran sobre todo la gran variedad de posibilidades y la inestabilidad del sistema de clíticos de objeto directo en el habla de las personas de este grupo generacional. Así, se registra el empleo del clítico la con referente masculino singular, con reduplicación (ejemplo 6) o sin ella con un referente humano (ejemplo 7) o no humano (ejemplo 8); también recogimos ejemplos de la con referente masculino plural (ejemplos 9 y 10):

(6). Antes yo me la sé el ciento por ciento del malecu.

(7). La gente la quedan viendo [a un señor que le habla en malecu].

(8). A mí me gusta freír pescado / frito me gusta / me gusta este: / cocinado / yo la aso así en el fuego y me la como.

(9). Yo no la conozco ellos.

(10). Porque esos chiquillos tuve eh: / cinco hijos / y el papá al tiempo me la llevó para: / para Guápiles / se fueron pequeñitos.

Asimismo, es común la neutralización del número a favor nuevamente del clítico lo, sea con referente masculino plural inanimado (ejemplo 11) o animado (ejemplo 12) y con reduplicación (ejemplo 13), sea con referente femenino plural inanimado (ejemplo 14) o animado humano (ejemplo 15):

(11). No soy egoísta / pero estos libros no se lo presto.

(12). Los niños / cuando están pequeñitos / hablan porque lo están / mejor dicho obligando.

(13). No importa que no lo sepa escribir los acentos.

(14). Porque hay palabras / en español / que no lo hay en malecu.

(15). Agarraron unas muchachas / tal vez de / digo yo que tal vez quince años / y el papá decía que no lo / que no lo agarre que no lo no tiene por qué violarlo. 
Si bien predomina estadísticamente en los contextos mencionados el clítico lo, las oraciones citadas muestran la reestructuración en su máxima expresión: se pueden neutralizar el género y el número, a la vez que se presenta la reduplicación con grupo nominal a la derecha (no a la izquierda con referente definido, como en español general). Asimismo, pareciera que a veces los clíticos están en variación libre (ejemplos 16 y 17), precisamente por acción de la neutralización en ciernes, e incluso recogimos varios casos de leísmo (ejemplo 18) y unos pocos de loísmo (ejemplos 19 y 20) y de laísmo (ejemplo 21), no incluidos en el cuadro anterior:

(16). Y la lavé los pescaditos y los tenía cocinando.

(17). Y a veces lo lleva [a la chiquita] y a veces le digo "no la lleve”.

(18). Ah yo no me le callo a ellos / yo le pongo en su lugar.

(19). Yo siempre hablo para mis hijos / y: yo lo hablo así en malecu.

(20). Casi casi lo / pegaba un mordisco en el en el brazo [una danta a un señor].

(21). El malecu llevaba un collar / y que ese collar la habló de larga distancia.

Por último, como ya se ha señalado, son comunes los casos de reduplicación con grupo nominal a la derecha, pero no únicamente como producto de la neutralización, sino también -y con bastante frecuencia- cuando lo alude a un referente masculino singular (ejemplos 22, 23 y 24):

(22). Los métodos que nosotros utilizamos para no: / herirlo algún animal.

(23). Gente blanco lo conoce el malecu / se echa de ver la carita.

(24). Dicen que lo mataron [los paisanos malecus] un sapersote [=sacerdote].

En suma, el habla de los ancianos y los adultos mayores se caracteriza por una gran inestabilidad del sistema de clíticos de objeto, con múltiples neutralizaciones de género y de número (sin importar el rasgo de animidad) a favor predominantemente del clítico lo, pero con apariciones también frecuentes de la como archimorfema e incluso, aunque más esporádicamente, de los y las.

Por lo demás, al comparar el grupo de Margarita con el malecu como lengua dominante con el grupo con bilingüismo equilibrado, parece haber diferencia solo en lo que respecta a la reduplicación con referente masculino singular, fenómeno que también aparece en el habla de las personas de Tonjibe. En otras palabras, este es el único 
fenómeno que podría estar correlacionado con el momento de adquisición del español y con un dominio de esta lengua claramente subordinado al malecu en este grupo etario.

\subsection{Hablantes adultos y adultos jóvenes}

Los adultos (personas de entre 35 y 50 años) y los adultos jóvenes (individuos de entre 30 y 35 años), de acuerdo con nuestra tipología ad hoc, representan la generación de la transición. Los mayores de 35 años en Tonjibe declaran que su bilingüismo fue sucesivo, con el malecu como lengua materna, mientras que en muchos otros se trata de un bilingüismo simultáneo, con diversos desarrollos de la competencia productiva en un continuum de bilingüismo sumamente heterogéneo, dependiendo de la biografía de cada sujeto, la cual incluye fenómenos de adquisición incompleta y de atrofia lingüística en algunos. En el caso de Tonjibe, contamos con datos de dos grupos determinados por su competencia reportada en malecu.

Cuadro 3. Aparición de clíticos de objeto directo en el habla de adultos y adultos jóvenes

\begin{tabular}{|l|l|l|l|l|l|}
\cline { 2 - 6 } \multicolumn{1}{c|}{} & \multicolumn{1}{c|}{ Clítico } & \multicolumn{1}{c|}{ Margarita } & \multicolumn{1}{c|}{ El Sol } & \multicolumn{2}{c|}{ Tonjibe } \\
\cline { 2 - 6 } & & & & $\begin{array}{l}\text { Con español } \\
\text { dominante }\end{array}$ & $\begin{array}{l}\text { Con } \\
\text { bilingüismo } \\
\text { equilibrado }\end{array}$ \\
\hline Referente masc. singular & lo & $77 / 100 \%$ & $92 / 100 \%$ & $16 / 100 \%$ & $40 / 100 \%$ \\
\hline $\begin{array}{l}\text { Ref. masc. sing. con } \\
\text { reduplicación }\end{array}$ & lo & 0 & 0 & 0 & $1 / 100 \%$ \\
\hline $\begin{array}{l}\text { Referente femenino } \\
\text { singular }\end{array}$ & lo & $15 / 68 \%$ & $5 / 29 \%$ & $1 / 20 \%$ & $7 / 78 \%$ \\
\cline { 2 - 7 } & la & $7 / 32 \%$ & $12 / 71 \%$ & $4 / 80 \%$ & $2 / 22 \%$ \\
\hline Ref. masc. plural & lo & $6 / 24 \%$ & $8 / 73 \%$ & 0 & $2 / 100 \%$ \\
\cline { 2 - 7 } & los & $19 / 76 \%$ & $3 / 27 \%$ & 0 & 0 \\
\hline Ref. femenino plural & lo & $8 / 47 \%$ & $12 / 75 \%$ & $1 / 25 \%$ & $4 / 67 \%$ \\
\cline { 2 - 7 } & la & $1 / 6 \%$ & $1 / 6 \%$ & 0 & $2 / 33 \%$ \\
\cline { 2 - 7 } & los & $1 / 6 \%$ & 0 & 0 & 0 \\
\cline { 2 - 7 } & las & $7 / 41 \%$ & $3 / 19 \%$ & $3 / 75 \%$ & 0 \\
\hline
\end{tabular}


Lo primero que destaca en los datos de este grupo, en contraposición con los del grupo anterior, es la estabilización del sistema con una sola dirección en el proceso de neutralización del género, lo que implica que aparecen empleos de lo con referente femenino inanimado (ejemplos 25 y 26) y animado (ejemplo 27), pero no de la con referente masculino. Además, prácticamente desaparece la reduplicación (únicamente encontramos un caso en el corpus de Tonjibe: ejemplo 28). En lo que respecta al plural, las neutralizaciones a favor de lo con referente femenino inanimado (ejemplo 29) y animado (ejemplo 30) son más comunes que a favor de la con referente inanimado (ejemplo 31) o animado (ejemplo 32):

(25). Porque después de la canción / yo tengo que traducírselo.

(26). La sangre malecu lo lleva ella.

(27). No puedo este / voltear a verlo a ella.

(28). Sí lo hablamos también el malecu.

(29). Hay cosas todavía digamos que: / que quizás digamos a mí no me lo han enseñado.

(30). Aquí lo que tienen que hacer ustedes es / dejen a sus mujeres / y y despídelo.

(31). Entonces las palabras que él le va diciendo / ellas la interpretaban en son de burla.

(32). “¿Usted come este / iguanas?” / “ah sí claro yo me la como”.

Sin embargo, todavía en este grupo se hallan ejemplos de aparente variación libre entre lo y la (ejemplo 33) y entre lo y los (ejemplo 34):

(33). Esa información yo nunca pude obtenerla / sin embargo / yo hablaba con don O. un día / y vieras que hay palabras en malecu / que yo mismo no las sé / y yo digo que / yo te digo que yo te hablo un ochenta por ciento malecu / y yo digo “dios mío pero / pero entonces quiere decir que yo no sé hablar malecu” / y y R. / me dijo unas palabras O. en malecu / que al final dije yo "pero y / ¿dónde este hombre aprendió todas estas cosas?” / y y entonces este / y y yo sé que / A. / está: / rico en esas informaciones / que aún nosotros no lo tenemos / más bien / yo no sé cómo contactar a: ese señor / y decirle / "vea / dame toda la información que usted tenga porque yo lo ocupo. 
(34). ¿Por qué no vamos y y y llevamos cámara / este para para filmar todo ese / todo lo que ustedes los discriminan de la forma que a ustedes lo agarran como delincuentes y encañonarlo y toda esa cosa?”

Si bien, en contraste con el grupo con bilingüismo equilibrado de Tonjibe, parecen más bien esporádicas las neutralizaciones de género y número a favor del clítico lo en el grupo de hablantes con el español como idioma dominante de esta misma comunidad, no puede obviarse el hecho de que estas aún aparecen, lo que muestra que el cambio forma parte del sistema de hablantes que incluso declaran competencia productiva muy restringida en malecu.

\subsection{Hablantes jóvenes}

La heterogeneidad de la situación sociolingüística hallada en el grupo anterior continúa en el grupo de jóvenes (con edades entre los 14 y los 30 años), pero con una evidente tendencia a la reducción de la competencia productiva en malecu, el semilingüismo y la paulatina merma de la competencia receptiva también. No obstante, el bilingüismo relativamente equilibrado o al menos la capacidad productiva desarrollada en malecu es más común entre los jóvenes de Tonjibe que en los muchachos de las otras dos comunidades. Solo las circunstancias biográficas particulares explican que haya bilingües simultáneos en Margarita o El Sol.

Cuadro 4. Aparición de clíticos de objeto directo en el habla de jóvenes

\begin{tabular}{|l|l|l|l|l|}
\cline { 2 - 5 } \multicolumn{1}{c|}{} & \multicolumn{1}{c|}{ Clítico } & \multicolumn{1}{c|}{ Margarita } & \multicolumn{1}{c|}{ El Sol } & \multicolumn{1}{c|}{ Tonjibe } \\
\hline Referente mas. sing. & lo & $109 / 100 \%$ & $15 / 100 \%$ & $74 / 100 \%$ \\
\hline $\begin{array}{l}\text { Referente femenino } \\
\text { singular }\end{array}$ & lo & $4 / 31 \%$ & $1 / 50 \%$ & $18 / 53 \%$ \\
\cline { 2 - 6 } & la & $9 / 69 \%$ & $1 / 50 \%$ & $16 / 47 \%$ \\
\hline $\begin{array}{l}\text { Referente masculino } \\
\text { plural }\end{array}$ & lo & $4 / 31 \%$ & $1 / 50 \%$ & $7 / 32 \%$ \\
\cline { 2 - 6 } & los & $9 / 69 \%$ & $1 / 50 \%$ & $15 / 68 \%$ \\
\hline \multirow{2}{*}{$\begin{array}{l}\text { Referente femenino } \\
\text { plural }\end{array}$} & lo & $5 / 36 \%$ & $2 / 67 \%$ & $10 / 71 \%$ \\
\cline { 2 - 6 } & la & $2 / 14 \%$ & 0 & $2 / 8 \%$ \\
\cline { 2 - 5 } & las & $7 / 50 \%$ & $1 / 33 \%$ & $2 \%$ \\
\hline
\end{tabular}


El corpus de los grupos de jóvenes de las tres comunidades muestra las mismas tendencias de neutralización encontradas en el grupo de adultos, sin que se aprecien diferencias evidentes entre las comunidades, lo que confirma que definitivamente no se trata de variaciones propias de la interlengua de aprendices tardíos del español, sino de un proceso de cambio a favor del archimorfema lo con referente femenino singular (ejemplos 35 y 36), femenino plural (ejemplo 37) o masculino plural (ejemplo 38), si bien también registramos empleos de la con referente femenino plural (ejemplo 39) e incluso variación libre entre lo y las (ejemplo 40):

(35). Una vez yo le hice una pregunta a mi abuela / y diay ella no me lo supo: contestar en español.

(36). Si esa timidez usted no se lo sabe quitar ahorita nunca se lo va a quitar.

(37). Hay palabras malas que yo no me atrevo ni a / ni a decirlo ni en español.

(38). Yo no sé si ellos lo hacen solo por eso / para que no / no lo discriminen.

(39). Las narraciones en malecu y todo eso / no me / algunas no me la sé.

(40). Porque hay palabras / que aquí uno las pronuncia bien / y él lo va a pronunciar diferente.

\subsection{Hablantes niños}

Los niños de Tonjibe, único grupo de este rango de edad para el que hemos recogido datos, muestran mayor competencia receptiva que sus coetáneos de Margarita y El Sol, pero la competencia productiva no parece ser mucho mayor. Salvo un par de excepciones -no incluidas en el corpus analizado-, todos tienen el español como lengua materna y dominante.

Cuadro 5. Aparición de clíticos de objeto directo en el habla de niños

\begin{tabular}{|l|l|l|}
\cline { 2 - 3 } \multicolumn{1}{c|}{} & \multicolumn{1}{c|}{ Clítico } & \multicolumn{1}{c|}{ Tonjibe } \\
\hline Referente masculino singular & lo & $14 / 100 \%$ \\
\hline \multirow{2}{*}{ Referente femenino singular } & lo & $1 / 50 \%$ \\
\cline { 2 - 3 } & la & $1 / 50 \%$ \\
\hline
\end{tabular}




\begin{tabular}{|l|l|l|}
\hline \multirow{2}{*}{ Referente masculino plural } & lo & $1 / 33 \%$ \\
\cline { 2 - 3 } & los & $2 / 66 \%$ \\
\hline Referente femenino plural & lo & $1 / 100 \%$ \\
\hline
\end{tabular}

A pesar de que nuestros datos son muy exiguos, no deja de llamar la atención que se haya recogido al menos un caso de neutralización de género a favor de lo (ejemplo 41) y de neutralización de número también a favor de lo con referente masculino (ejemplo 42) y otro con referente femenino (ejemplo 43) en un grupo cuya lengua materna es sin lugar a dudas el español y que muestra solo competencia pasiva reducida o, en el mejor de los casos, semilingüismo en malecu:

(41). Una palabra que no / no lo hice.

(42). Todos los chiquillos de Margarita no saben hablar en español / y el maestro lo regañaba porque no no hablaban.

(43). En veces nos / pasa a la pizarra a contestar unas cosillas en malecu / y hay que contestarlo / en español.

\subsection{El corpus de elicitación controlada y los datos de habla espontánea}

Por medio de datos recogidos por elicitación controlada, así como de los datos de habla espontánea que hemos podido registrar, podemos confirmar la ubicuidad de las neutralizaciones y de las alternancias entre lo y la en el discurso de hablantes de las tres comunidades y de todos los grupos etarios. Compárense los siguientes ejemplos: el 44 de una hablante de Margarita, el 45 y el 46 de jóvenes de Tonjibe, las tres con bilingüismo equilibrado, y el 47 de un joven de Tonjibe con competencia receptiva:

(44). La compro en el supermercado [la cebolla] / la lavo / la pelo / la hago en rodajas / la pico y luego se lo agrego a los alimentos que estoy cocinando.

(45). La cebolla / lo pelo / luego de pelarla lo lavo / después de lavarlo si tengo que partirlo a la mitad.

(46). Entonces lo revisamos ver si ya está empapada [la niña] / entonces le quitamos la mantilla / entonces ya lo cambiamos (...) después la baña / ella lo baña (...) / cuando ella lo termina bañar / la muda y le pone los zapatitos / lo 
peina / le hace unos colochos (...) después ella quiere que uno lo lleve pasear a algún lado / después de ahí lo entretenemos con juguetes.

(47). La cebolla la picamos / (...) lo podemos calentar un momento ahí con el aceite.

Por último, los siguientes ejemplos tomados del habla de una anciana de Tonjibe, con un claro bilingüismo subordinado al malecu, muestran cómo su sistema de clíticos incluye otras posibilidades, muchas de las cuales luego serán descartadas en el sistema de las generaciones sucesivas: reduplicación con referente masculino singular (ejemplo 48), reduplicación con referente femenino singular (ejemplo 49), leísmo con referente femenino singular (ejemplos 50 y 51), leísmo y reduplicación con referente femenino singular (ejemplo 52):

(48). Lo cocinó plátano para comer con esa comida.

(49). Lo ponieron la ropita también.

(50). Yo le picó [la cebolla] y yo le echó en manteca.

(51). Le peinaron [a la chiquita].

(52). Yo le agarré esa niña.

4. Cambios inducidos por contacto en el sistema pronominal átono de tercera persona en el español malecu

El fenómeno de variación de clíticos de acusativo de tercera persona del que dimos cuenta líneas atrás no ha sido reportado en ninguna de las caracterizaciones de las variedades del español costarricense sin contacto con una lengua amerindia (Agüero 2009; Arroyo 1971; Quesada 1990, 1991, 2009, 2010); tales fuentes más bien señalan la prevalencia del sistema etimológico, con apenas algunos casos muy puntuales de leísmo.

Por consiguiente, dicha variación en el español hablado por los malecus constituye un cambio que ha de explicarse por el factor exógeno más claramente vinculado a esta situación particular: el cambio inducido por el contacto prolongado e intenso con la lengua malecu que ha desencadenado reacomodos del subsistema pronominal átono en 
español. Así, se hace necesario el examen de de las características estructurales del idioma malecu vinculadas con el fenómeno en estudio.

El malecu es una lengua ergativa con marcación obligatoria tanto del caso absolutivo como del ergativo por medio de prefijos verbales (Constenla 1998). La serie absolutiva incluye los prefijos na- 'primera persona singular y primera persona plural exclusiva', mi- ma- 'segunda persona', i- a- 'tercera persona', ma- 'primera persona plural inclusiva', mientras que la serie ergativa incluye los prefijos rra- 'primera persona singular y primera persona plural exclusiva', rrifa- (y varios alomorfos) 'segunda persona', rri- 'tercera persona', ri- 'primera persona plural inclusiva', como se muestra en los siguientes ejemplos tomados de Constenla: natóye 'voy', itóye 'va', arrácuánhe 'lo veo', irrícuánhe 'lo ve’.

De acuerdo con la descripción del habla más tradicional y conservadora que lleva a cabo Constenla (1998), el prefijo de absolutivo de tercera persona se realiza como cero, especialmente si va precedido por el grupo nominal correferencial o cuando va antecedido por alguna palabra y aparece en combinación con un prefijo de la serie ergativa o de la voz reflexivo-recíproca. Así, uno de los ejemplos que consigna Constenla es el siguiente, en el cual el prefijo de absolutivo de tercera persona se realiza como cero en el verbo tóye (cf. itóye ‘él fue’): iochá tóye 'su marido se fue’. No obstante, nuestra impresión es que esta regla está cambiando rápidamente, pues incluso se encuentran ejemplos, en el habla de personas ancianas, que parecen ir contra esta descripción.

En términos contrastivos entre la gramática del malecu y la gramática del español, cabría señalar que el sistema de prefijos de persona en malecu no expresa distinciones de género (de hecho, existen algunos pocos casos de lexicalización del sexo, pero no de gramaticalización) ni de número (aunque el número sí está gramaticalizado y se expresa recurrentemente en el discurso por medio del marcador maráma -o algún alomorfopospuesto tanto a raíces nominales como verbales), contrario a lo que ocurre en español. La animidad no se codifica gramaticalmente en malecu ni parece tener mayor incidencia en la estructura morfosintáctica de la lengua más allá de dar cuenta, aparentemente, de la mayor frecuencia de desplazamientos de grupos nominales argumentales a la derecha del verbo (Krohn 2011). 
Así las cosas, la obligatoriedad de la expresión de la persona por medio de los prefijos verbales, equivalentes semántico-pragmáticos a los clíticos de objeto directo del español, explica que en nuestros datos del español hablado por individuos malecus no aparezcan ejemplos de elisión de clíticos, ni siquiera en las muestras de habla de personas ancianas, como sí se ha descrito para otras variedades de español de contacto (Palacios 2013). Por su parte, la neutralización del género (y en menor medida del número) mediante el clítico lo tendría su origen en la ausencia de gramaticalización de tales nociones en el sistema de prefijos de persona del malecu, lo cual habría desencadenado la inestabilidad de la codificación de las categorías de género y número del grupo nominal correferencial en el clítico de objeto directo del español.

El español hablado por los malecus, además, muestra cómo los cambios no se han producido en el sistema de casos, aspecto para el cual -como ya lo anotamos- las variedades del español costarricense sin contacto con otras lenguas se atienen, con muy pocas excepciones, al sistema etimológico. Esto es así porque la gramática del malecu distingue con claridad el ergativo y el absolutivo (ambos casos nucleares marcados en la flexión verbal, correspondientes al nominativo y el acusativo del español, según la transitividad del verbo) del dativo, que se codifica como caso periférico mediante un grupo posposicional (Constenla 1998).

Por otra parte, la neutralización de la categoría de número en los clíticos de dativo en el español malecu -del cual no dimos cuenta en el presente trabajo, por lo cual se requiere realizar un análisis pormenorizado al respecto - parece profundizar el fenómeno de cambio en marcha en la misma dirección, muy avanzado en el español costarricense en general (Sánchez 2008), de modo que vendría a reforzar la tesis del reacomodo del sistema pronominal átono de tercera persona en su totalidad por influjo de las categorías que son pertinentes o no en la gramática del malecu. El ejemplo 53 muestra una neutralización de número coincidente con la tendencia en el español de Costa Rica (Sánchez 2008), mientras que el 54 representaría el cambio más avanzado en el español malecu (ambos son extraídos del mismo corpus analizado en este trabajo): 
(53). A los compañeros yo le hablo por asunto de trabajo nada más.

(54). Ellos me me me entienden lo que yo le digo.

Si la presión normativa que lleva al restablecimiento del sistema etimológico con marcación de caso y género en los clíticos de acusativo -con mucha probabilidad por influencia de la escolarización generacionalmente creciente de los miembros del pueblo malecu y el influjo de la variedad nacional de prestigio- no estuviera actuando en el aparente retroceso del fenómeno de cambio descrito, muy probablemente este desem-bocaría en un sistema bimembre en el que solo importaría la marcación del caso acusativo frente al dativo, con neutralización del género y el número, en parangón con el sistema malecu de ergativo/absolutivo frente a dativo, sin codificación del género y el número.

El que la neutralización del número en los clíticos de dativo no muestre este retroceso, sino que más bien siga la tendencia predominante en el español costarricense de prestigio, pese a los posibles intentos de la escuela de evidenciar la discordancia, reforzaría la tesis de la relevancia de la acción normativa cuando la variedad surgida por contacto muestra cambios radicalmente divergentes de la variedad sin contacto $\mathrm{y}$ de prestigio, sobre todo tratándose de un grupo demográficamente pequeño, como el malecu, que debe funcionar en un mundo hispanohablante.

Queda por explicar únicamente el fenómeno de la reduplicación en el habla de los ancianos. La coaparición de grupos nominales correferenciales a los prefijos de caso en malecu está determinada muchas veces por factores pragmático-discursivos (Krohn 2012), pero por lo demás resulta bastante común como estrategia para especificar el contenido codificado por los prefijos (Constenla 1998; de quien tomo los ejemplos aunque con modificaciones en la traducción morfemática), como se muestra a continuación:

(55). Ochápacá curíjurí rri-cuánhe 'el hombre vio a la mujer’.

hombre mujer 3erg-vio

(56). I-rrí-cuánhe curíjurí ochápac 'el hombre vio a la mujer’.

3abs-3erg-vio mujer hombre 
Además, es muy común en la lengua que se coloque el pronombre catafórico "vacío” ní 'este’ en posición preverbal y luego un grupo nominal correferencial en posición posverbal que aclare el contenido semántico referencial de este (ejemplo 57), o bien que se codifique el participante mediante el prefijo de persona y que en posición posverbal se incluya el grupo nominal correferencial (ejemplos 58 y 59) respectivo:

(57). Ní a-rra-cuánhe yári 'vi un jaguar’. esto 3abs-1erg-vi jaguar

(58). I-tóye María 'María se fue’.

3abs-fue María

(59). A-rra-cuánhe yári 'vi un jaguar’.

3abs-1erg-vi jaguar

En nuestra opinión, esta característica estructural del malecu está detrás de la aparición de las reduplicaciones con grupo nominal correferencial a la derecha del verbo, registrado en el corpus de los hablantes ancianos y adultos mayores. Empero, tal cambio no parece haberse consolidado ni continuado en las demás generaciones con bilingüismo equilibrado o bilingüismo subordinado al español.

\section{Conclusiones}

La propuesta explicativa de Palacios (2011) en cuanto a los cambios inducidos por contacto en general y, en particular, en lo concerniente a la reestructuración del sistema pronominal átono de tercera persona se ve corroborada completamente en los datos analizados en este trabajo con respecto al español hablado por los malecus de Costa Rica: las características estructurales de la lengua malecu en lo relativo a la codificación gramatical de los participantes del evento por medio de la distinción de caso (aunque con un sistema distinto al del español, lo que evidencia que no estamos ante una transferencia directa: se trata de prefijos verbales de ergativo y absolutivo en malecu y de clíticos verbales de objeto directo e indirecto en español) calzan con el sistema pronominal etimológico del español costarricense en este aspecto, pero motivan la neutralización de las categorías de género y número, codificadas en el sistema del español pero no en el del malecu. 
Asimismo, se aprecia cómo el tipo de bilingüismo (correlacionado con la variable etaria y la comunidad de origen en el caso malecu) está vinculado a la mayor o menor prevalencia de las neutralizaciones, aunque ciertamente en todos los grupos generacionales de las tres comunidades se registraron ejemplos del fenómeno de reestructuración, si bien con menor frecuencia conforme avanza el monolingüismo en español. Es probable que la acción de la convergencia hacia la variedad de habla prestigiosa en Costa Rica (la del Valle Central, que incluye la capital), promovida por el sistema escolar y los medios de comunicación de masas, influya en la menor frecuencia del fenómeno de cambio y en su paulatino retroceso en las nuevas generaciones.

Bibiografía

Agüero, A. (2009). El español de Costa Rica. San José: Editorial de la Universidad de Costa Rica.

Appel, R. y Muysken P. (1996). Bilingüismo y contacto de lenguas. Barcelona: Ariel.

Arroyo, V. (1971). El habla popular en la literatura costarricense. San José: Publicaciones de la Universidad de Costa Rica.

Blas, J. (2008). Sociolingüística del español. Desarrollos y perspectivas en el estudio de la lengua española en contexto social. Madrid: Cátedra.

Castillo, R. (2004). An Ethnogeography of the Maleku indigenous peoples in Northern Costa Rica. Tesis doctoral, Universidad de Kansas.

Constenla, A. (1988). El guatuso de Palenque Margarita: Su proceso de declinación. Estudios de Lingüística Chibcha, 7, 7-37.

Constenla, A. (1998). Gramática de la lengua guatusa. Heredia: Editorial de la Universidad Nacional de Costa Rica.

Constenla, A. (2005). Algunos aspectos lingüísticos y socioculturales de la influencia de las lenguas indígenas en las variedades americanas del español. Boletín de la Academia Costarricense de la Lengua, 1, 65-86. 
Krohn, H. (2011). La representación sintáctica de la topicalidad de los participantes discursivos en la narrativa tradicional malecu. Estudios de Lingüística Chibcha, 30, 37-62.

Krohn, H. (2012). El mantenimiento de la referencia anafórica en el discurso narrativo tradicional en lengua malecu. Revista de Filología y Lingüística, 38 (1), 191-216.

Palacios, A. (2008). Introducción. A. Palacios (coord.), El español en América. Contactos lingüísticos en Hispanoamérica. Barcelona: Ariel, 11-15.

Palacios, A. (2011). Nuevas perspectivas en el estudio del cambio inducido por contacto: hacia un modelo dinámico del contacto de lenguas. Lenguas Modernas, 38, 17-36.

Palacios, A. (2013). Contact-induced change and internal evolution. Spanish in contact with Amerindian languages. Léglise, I y Chamoreau C. (eds.), The Interplay of Variation and Change in Contact Settings. Amsterdam: John Benjamins Publishing Company, 165-198.

Porras, A. (1959). El idioma guatuso. Tesis de licenciatura, Universidad de Costa Rica.

Quesada, M. (1990). El español colonial de Costa Rica. San José: Editorial de la Universidad de Costa Rica.

Quesada, M. (1991). El español de Guanacaste. San José: Editorial de la Universidad de Costa Rica.

Quesada, M. (2008). América Central. A. Palacios (coord.), El español en América. Contactos lingüísticos en Hispanoamérica. Barcelona: Ariel, 57-75.

Quesada, M. (2009). Historia de la lengua española en Costa Rica. San José: Editorial de la Universidad de Costa Rica.

Quesada, M. (2010). Atlas lingüístico-etnográfico de Costa Rica. San José: Editorial de la Universidad de Costa Rica.

Sánchez, C. (2008). El uso de 'le’ por 'les’ en el español costarricense: de la cohesión a la morfologización. Revista Internacional de Lingüística Iberoamericana, 6 (1), 111-127. 
Sánchez, C. (2011). Caracterización cualitativa de la situación sociolingüística del pueblo malecu. Estudios de Lingüística Chibcha, 30, 63-90.

Sánchez, C. (2013). Lenguas en peligro en Costa Rica: vitalidad, documentación y descripción. Káñina, 37(1), 219-250.

Sánchez C. (en preparación). El español hablado por los malecus: Caracterización general y reconocimiento como variedad etnolectal.

Solórzano, J. (2013). Los indígenas en la frontera de la colonización. Costa Rica 15021930. San José Editorial de la Universidad Estatal a Distancia.

Recibido: 1 de febrero de 2015 Aceptado: 4 de febrero de 2015

Publicado: 28 de febrero de 2015 